\title{
A COMPARATIVE STUDY OF MICROWAVE AND BARRIER DISCHARGE PLASMA FOR THE REGENERATION OF SPENT ZEOLITE CATALYSTS
}

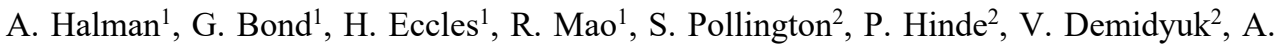 Gkelios $^{2}$
${ }^{1}$ Centre for Materials Science, University of Central Lancashire, Preston, PR1 2H,.UK.
${ }^{2} J o h n s o n$ Matthey Technology Centre, PO Box1, Belasis Avenue, Billingham, Cleveland, $T S 231 L B, U K$.
gbond@uclan.ac.uk

Keywords: microwave, barrier discharge, plasma, catalyst, toluene disproportionation.

\section{Introduction}

Due to their acid characteristics and pore structure, which can induce high product selectivity; zeolite catalysts are used extensively in industry to catalyse reactions involving hydrocarbons. However, these catalysts can suffer from deactivation due to cracking reactions that result in the deposition of carbon leading to poisoning of the acid sites and blocking of the pores [1]. Depending upon the reaction and the particular catalyst involved, this deactivation may take place over several months or even years but in some cases occurs in minutes. Therefore, zeolite catalysts are frequently reactivated / regenerated. This generally comprises of a thermal treatment involving air which results in oxidation of the carbon [2]. However, the oxidation of carbon is highly exothermic, and if not carefully controlled, results in the generation of exceedingly high localized temperatures which can destroy the zeolite structure and lead to subsequent loss of catalyst activity. More conservative thermal treatments can result in incomplete regeneration and again a catalyst displaying inferior activity.

This paper explores the use of non-thermal plasma which had been generated using either microwaves or via a barrier discharge to regenerate spent zeolite catalysts. The catalyst, Hmordenite, was tested for the disproportionation of toluene (Figure 1) using conventional heating. The spent catalyst was then regenerated using a plasma or conventional thermal treatment before having its activity re-evaluated for the toluene disproportionation reaction as previous.
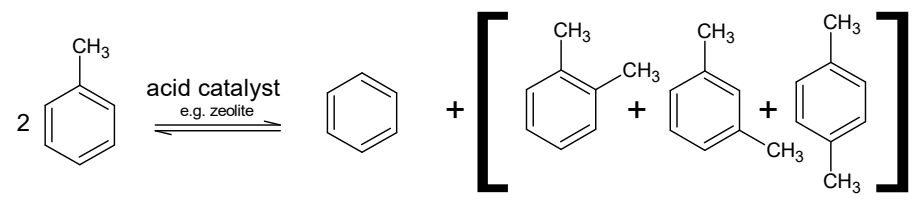

Fig. 1. Reaction Scheme for Toluene Disproportionation.

\section{Experimental}

\section{Catalyst Testing}

Virgin mordenite ( 700 mg) was packed into a fixed-bed borosilicate microreactor containing a thermocouple well and plugged with glass wool (total reactor bed volume: 1.79 $\mathrm{cm}^{3}$ ). The microreactor was enclosed within a temperature programmed furnace and connected to a nitrogen supply $\left(20 \mathrm{ml} \mathrm{min}^{-1}\right)$ regulated by a mass flow controller. The 
catalyst was calcined for 1 hour at $300^{\circ} \mathrm{C}$ after which the temperature was increased to $500^{\circ} \mathrm{C}$ prior to switching the toluene reactant feed on. The toluene was supplied by a gas saturator fitted with a sinter which was attached to the gas line before the microreactor. The saturator was submerged in an ice bath to regulate the temperature of the toluene and provide a constant partial pressure of toluene in the reactor feed gas. The toluene disproportionation reaction was studied for a period of 600 minutes. The output gas line was heated using heating tape (to $150^{\circ} \mathrm{C} \pm 3^{\circ} \mathrm{C}$ ) which was connected to a controller.

The exit gas was periodically sampled using air actuated sampling valves and the reactant / products analysed using online gas chromatography / mass spectrometry (GC/MS). The GC was fitted with a Supelco SupelcowaxTM 10 fused silica capillary column $(30 \mathrm{~m})$. This provided base line resolution of all products including the individual xylene isomers.

\section{Catalyst Regeneration}

Three regeneration methods were employed, all or which involved treating the spent catalyst in an oxidising environment in order to remove the deposited carbon from the surface of the catalyst. Two plasma techniques were employed: one using a plasma generated under low pressure utilising microwaves $(2.45 \mathrm{GHz})$ in a TE010 single mode cavity [3], the other utilising high voltages in a barrier discharge system to generate plasma at atmospheric pressure.

Microwave plasma experiments were performed in a 30\% oxygen in argon atmosphere (30 $\left.\mathrm{ml} \mathrm{min}^{-1}\right)$. Experiments were performed to optimise the regeneration conditions by independently varying the microwave power and consequently the wall temperature of the reactor which was monitored with an infrared pyrometer $\left(150-350^{\circ} \mathrm{C}\right)$. In separate experiments the pressure was also altered by varying the pumping conditions in order to achieve pressures in the range 5-50 mbar. During which the reactor wall temperature was maintained constant at $250^{\circ} \mathrm{C}$. Regeneration was carried out for a period of 7 hours.

The dielectric barrier discharge experiments were performed in $20 \%$ oxygen in argon at atmospheric pressure $\left(100 \mathrm{ml} \mathrm{min}^{-1}\right)$ in a reactor configuration similar to that used by Di et. al. [4]. The peak to peak voltage used was $20 \mathrm{kV}$ at a frequency of $10 \mathrm{~Hz}$, the power consumption was $17 \mathrm{~W}$. The discharge gap between the electrodes was $5 \mathrm{~mm}$. Regeneration of the spent catalyst was carried out for a period of 8 hours.

A thermal regeneration was also carried out using a tube furnace set to $500^{\circ} \mathrm{C}$. The sample was regenerated in air $\left(20 \mathrm{ml} \mathrm{min}^{-1}\right)$ for a period of 24 hours. Previous studies had shown that the reduced regeneration times utilising conventional heating did not result in complete removal of the deposited carbon.

Regenerated catalysts were then re-tested for their activity for the toluene disproportionation reaction. Post-mortem analysis was performed using X-ray diffraction to determine if the regeneration technique had resulted in degradation to the zeolite structure. The efficacy of the regeneration techniques was checked using thermogravimetric analysis (TGA) to determine the extent of carbon removal from the catalyst.

\section{Thermogravimetric analysis (TGA)}

Carbon content of deactivated and regenerated catalysts was determined using TGA (Mettler Toledo TGA1 STARe System), with the mass loss at $500^{\circ} \mathrm{C}$ attributed to loss of coke. Samples were analysed using a complex thermal programme that involved heating the sample in air to a temperature of $800^{\circ} \mathrm{C}$; which had previously been validated for this type of analysis [5]. 


\section{Powder X-ray diffraction (XRD)}

$\mathrm{XRD}$ analysis was carried out on catalyst samples to determine any crystalline changes that regeneration may have had on the sample. Samples were ground using a mortar and pestle prior to analysis using a Bruker D2 Phaser diffractometer and nickel filtered copper $\mathrm{K} \alpha$ radiation $(0.154 \mathrm{~nm})$.

\section{Results and Discussion}

\section{Thermal Regeneration of Spent H-mordenite}

Toluene conversion over a new (virgin) sample of H-mordenite is shown in Figure 2. It can be seen that the activity decreased from an initial conversion of approximately $61 \%$ to $8 \%$ over a period of 600 minutes. The decrease in catalytic activity can be attributed to competing cracking reactions that result in the deposition of carbon on the surface of the catalyst. The catalyst on discharge from the reactor had visibly changed from its original white colour to black. TGA analysis of the spent sample showed that $4.55 \mathrm{wt} \%$ carbon had been deposited during the course of the reaction. The TGA analysis also indicated that a regeneration temperature of $500^{\circ} \mathrm{C}$ was necessary to remove in excess of $95 \%$ of the carbon. Studies to determine the time necessary to achieve this level of regeneration indicated that a reaction time in excess of 16 hours was required and this was standardised to 24 hours for all conventionally heated regenerations. The thermally regenerated catalyst was re-tested to determine its activity for toluene disproportionation as a function of time (Figure 2). The results showed that the regenerated catalysts displayed a slightly lower initial activity of approximately $58 \%$ and then displayed a very similar activity time profile to the virgin catalyst. The slightly reduced initial activity may be the result of a small amount of carbon still remaining in a highly graphitic form after regeneration, TGA studies of the regenerated catalyst did show that $0.36 \mathrm{wt} \%$ carbon remained in the structure. The XRD pattern of the thermally regenerated catalyst (Figure 5) indicates that the structure of the zeolite was not affected by the regeneration process. However, the initial benzene to xylene ratio is noticeably less than the in the virgin catalyst (Figure 6). For pure toluene disproportionation the benzene to xylene ratio should be approximately 1.0 [6]. However, it has been shown to be highly dependent upon operating conditions [7]. Under the operating conditions that have been chosen for this study where the aim was to achieve high rates of carbon deposition a benzene to xylene ratio less than 1 was observed. However, comparing the benzene to xylene ratio of the virgin and thermally regenerated catalyst it can be seen that the thermally regenerated catalyst exhibits a lower benzene to xylene ratio which is indicative that the catalyst has fewer strong acid sites which are known to catalyse the cracking reaction [8]. 


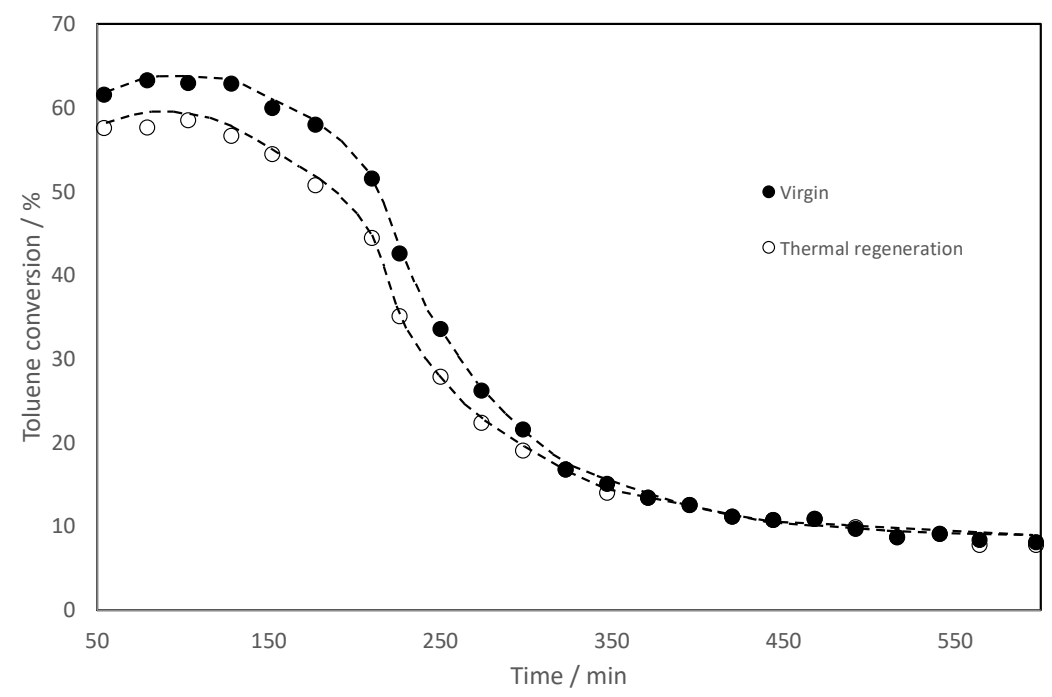

Fig.2. Plot of toluene conversation over a virgin and thermally regenerated H-mordenite catalyst.

Microwave Plasma Regeneration of Spent H-mordenite

The microwave powers required to attain wall temperatures in the range $150-350{ }^{\circ} \mathrm{C}$ are contained in Table 1. Figure 3 contains the activity time profiles for the re-testing of the regenerated catalysts. The figure clearly shows that the microwave power / temperature has a dramatic effect on the resulting catalyst activity. The catalyst regenerated at $150^{\circ} \mathrm{C}$ shows a modest initial activity ( $55 \%$ ), however, the catalyst rapidly deactivates with the activity falling to less than $10 \%$ over a period of 200 minutes. While from its external appearance the catalyst extrudate appeared to have undergone regeneration due to their white colour; when the catalysts were sectioned they clearly contained un-oxidised carbon in their core (Figure 3A). Therefore, the regenerated catalyst will have a reduced number of active (acid) sites which accounts for the rapid deactivation. The initial benzene to xylene ratio is indicative that some strong acid sites have been lost.

The catalyst regenerated at $250^{\circ} \mathrm{C}$ is interesting. The TGA data confirmed that almost all the carbon had been removed during the regeneration. The initial benzene to xylene ratio (Figure 6) is significantly lower than the virgin, thermal and microwave plasma $150^{\circ} \mathrm{C}$ regenerated catalysts. This provides evidence that the catalyst has fewer strong acid sites. Therefore, the catalyst is less likely to catalyse the cracking reaction. The consequence of which is that there is less carbon deposition and therefore the catalyst deactivates more slowly. The XRD pattern (Figure 5) confirms that the structural integrity of the catalyst is maintained during the regeneration. 


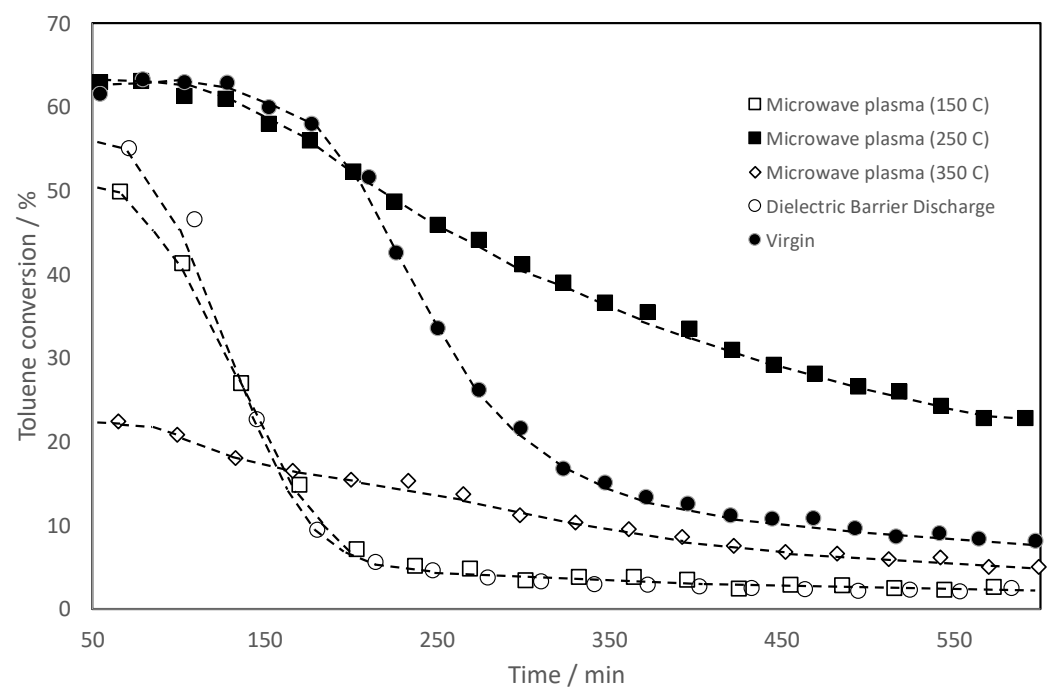

Fig.3. Toluene conversion over H-mordenite catalysts that have been regenerated using microwave plasma at varying temperatures / powers.

The catalyst regenerated at $350^{\circ} \mathrm{C}$ does not retain structural integrity as can be seen from the loss of intensity of the H-Mordenite peaks in the diffractogram (Figure 5). The initial benzene to xylene ratio is exceptionally low but so is the activity. This is indicative that a significant portion of the acid sites have been lost during the regeneration process.

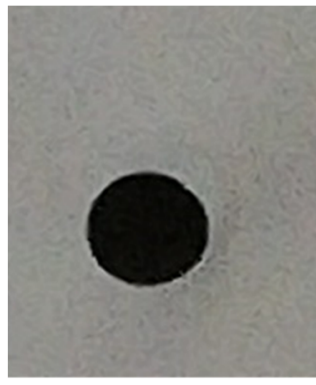

A

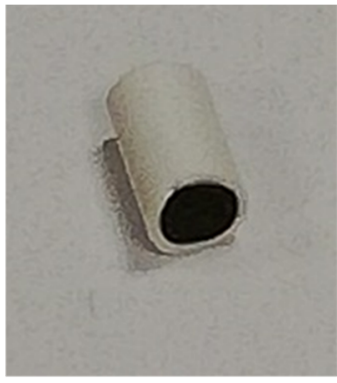

B

Fig.4. A Photograph of sectioned H-mordenite extrudate after microwave plasma regeneration at $150^{\circ} \mathrm{C}$, B Photograph of sectioned $\mathrm{H}$-mordenite extrudateafter dielectric barrier discharge plasma regeneration.

Table 1. Microwave power required to produce pre-set wall temperatures

\begin{tabular}{c|c}
\hline Wall temperature $/{ }^{\circ} \mathrm{C}$ & Microwave power $/ \mathrm{W}$ \\
\hline 150 & 125 \\
250 & 195 \\
350 & 400 \\
\hline
\end{tabular}




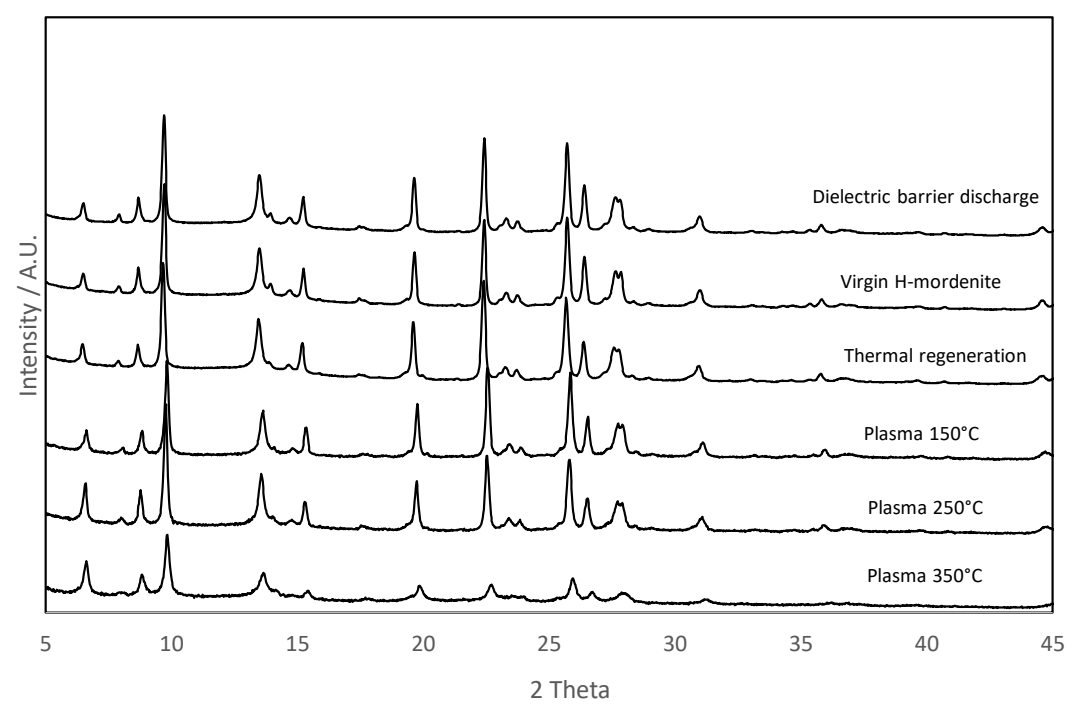

Fig.5. X-ray Diffractograms of virgin, thermal, microwave plasma and dielectric barrier discharge plasma regenerated catalysts.

The results from re-testing spent H-mordenite catalysts that had undergone microwave plasma regeneration in which the pressure of the microwave plasma had been varied between 5 and 50 mbar whilst keeping the reactor wall temperature constant at $250^{\circ} \mathrm{C}$ are shown in Figure 7. The microwave power used at both 5 mbar and 50 mbar was approximately 200 $\mathrm{W}$. The results confirm that microwave plasma offers a means of producing catalysts with resistance to deactivation. However, the pressure does appear to play a role. The catalyst regenerated at $5 \mathrm{mbar}$ has a greater resistance to deactivation than the catalyst regenerated at the higher pressure. The catalyst regenerated at $50 \mathrm{mbar}$ has a similar deactivation profile to the virgin catalyst, this is likely a result of the regeneration process not resulting in a significant reduction of acid sites as can be seen from the relatively high initial benzene to xylene ratio and consequently, there is significant cracking resulting in carbon deposition and deactivation of the catalyst. 


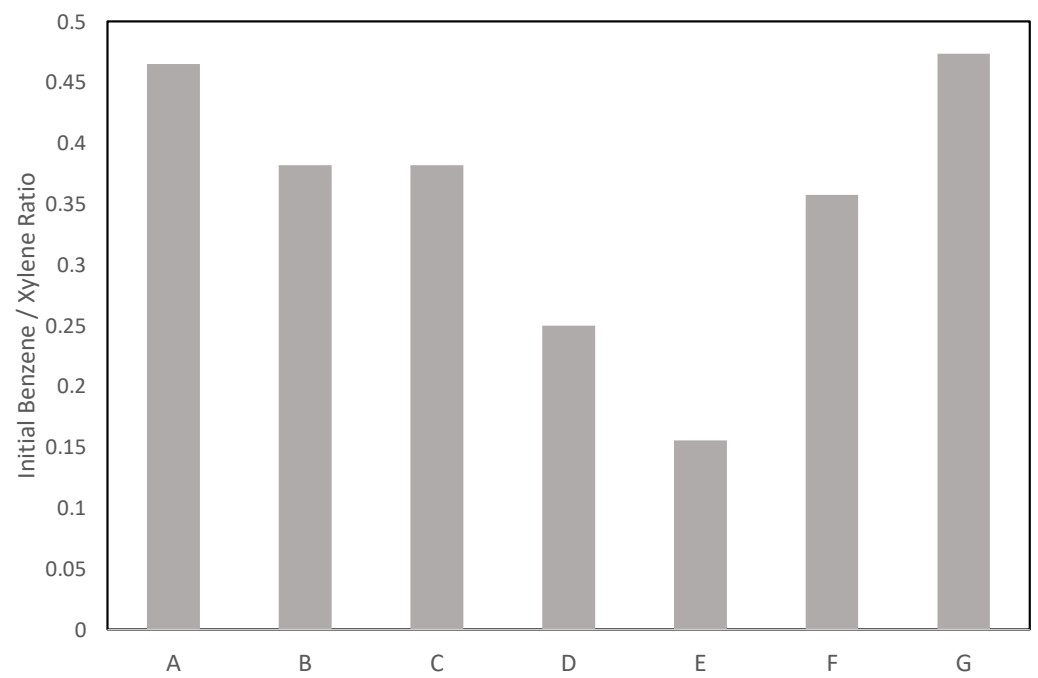

$\mathrm{A}=$ Virgin, $\mathrm{B}=$ Thermal regeneration, $\mathrm{C}=$ Microwave plasma $150^{\circ} \mathrm{C}, \mathrm{D}=$ Microwave plasma $250^{\circ} \mathrm{C}, \mathrm{E}=$ Microwave plasma $350^{\circ} \mathrm{C}, \mathrm{F}=$ Dielectric barrier discharge, $\mathrm{G}=$ Microwave plasma $250^{\circ} \mathrm{C}$ and $50 \mathrm{mbar}$.

Fig.6. Initial benzene to xylene ratios over H-mordenite catalysts that had been regenerated under different conditions.

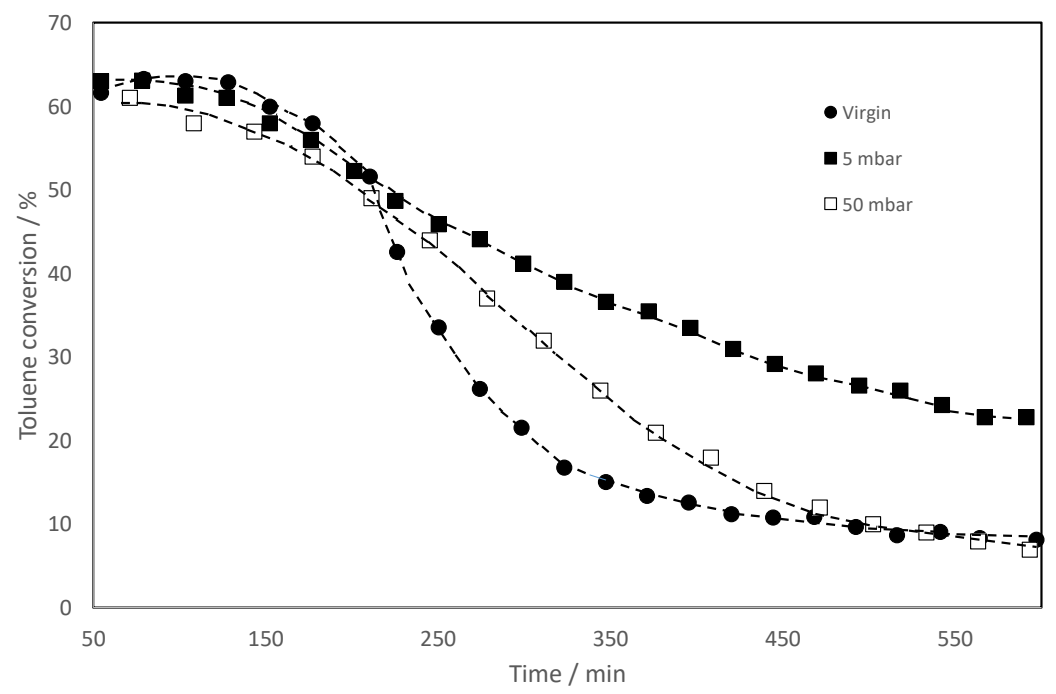

Fig.7. Toluene conversion over H-mordenite catalysts that have been regenerated using microwave plasma at varying pressures.

Dielectric barrier discharge plasma regeneration of spent H-mordenite

The sample of spent $\mathrm{H}$-mordenite which was regenerated using plasma generated using a dielectric barrier discharge method, displays an activity profile very similar to the sample regenerated using microwave plasma at $150^{\circ} \mathrm{C}$ (Figure 3). Considering the images shown in Figure 4 this is hardly surprising, as both catalysts have clearly not undergone full 
regeneration. The initial benzene to xylene ratio is also not dissimilar and consequently the number of strong acid sites would be expected to be similar.

\section{Conclusion}

The results from this study show that plasma regeneration of spent zeolite catalysts can be highly effective, not just through reducing the time required for regeneration but also through modifying the acid sites. The modification of strong acid sites, most probably occurs through dehydration of Brønsted acid sites. The modification to these strong acid sites reduces cracking reactions and consequently the amount of carbon that is deposited on the catalyst surface. This reduced carbon deposition results in extended catalyst lifetime. The study shows the microwave power / temperature used is critical as a power which is too low results in incomplete regeneration and a power which is too high can lead to loss of the structural integrity of the zeolite.

The study using plasma generated using dielectric discharge is at this stage inconclusive. If a more intense / energetic plasma was used, then it may be possible to achieve full regeneration. This fully regenerated catalyst may then display similar characteristics to the microwave plasma catalyst regenerated at $250^{\circ} \mathrm{C}$.

\section{References}

[1] Wu J., Leu L., Appl. Catal., 1983, 7, 283-294.

[2] M. Guisnet and P. Magnoux, Deactivation of Zeolites by Coking. Prevention of Deactivation and Regeneration. In: Zeolite Microporous Solids: Synthesis, Structure, and Reactivity. E.G. Derouane, F Lemos, C. Naccache, F. Ramôa Ribeiro, Eds. Pages 437-456. Springer 1992.

[3] Parkes, G.M.B., Bond, G., Barnes, P.A. and Charsley, E.L., Rev. Sci Instr., 2000, $71,168$.

[4] Di, L. Xu, Z., Wang, K. and Zhang, X. Catal. Today, 2013, 211, 109-113.

[5] Zhang, H., Shao, S., Xiao, R., Shen, K. and Zeng, J., Energy and Fuels., 2013, 28, 52-57.

[6] Kareem, A., Chand, S., and Mishra, I.M., J. Sci. Ind. Res., 2001, 60, 319-327.

[7] Tsai, T.C., Liu, S.B. and Wang, I., Appl. Catal. A. Gen., 1999, 181, 355-398.

[8] Gates, B. C., J. R. Katzer, and G. C. A. Schuit. Cracking. In: Chemistry of Catalytic Processes. B. C. Gates, J.R. Katzer and G.C.A. Schuit, Eds. Pages 1111. New York: McGraw-Hill, 1979. 